\title{
The logic of leverage: Reflections on post-foundational political economy
}

\author{
Martijn Konings \\ University of Sydney, Australia
}

Let me start by expressing my gratitude for these careful, generous and insightful readings of my book. If all engagements with other people's work lived up to the standards set by these reviews, academic life would be a very different and far more productive experience.

One particularly gratifying aspect of these reviews is that they recognize the significance of the notion of leverage. This concept has been central to my thinking as it has evolved over the course of the books I have written so far, and before engaging the specific issues raised by these reviews, it is useful here to restate, concisely and in plain terms, what work it was meant to do.

It has always been very hard for social scientists to think about power in a purely relational way - i.e., without assuming that it is 'held' by people or 'exists' in institutions. The widespread influence of post-foundational theory (broadly understood to include various strands of post-structuralism, post-modernism, constructivism and contemporary pragmatism) has of course provided plenty of avenues for de-essentializing social-scientific concepts. But it often seems that doing so, even when it is theoretically compelling and accompanied by a critical ethos, undermines our ability to elaborate a perspective that is critical in the substantive sense of being attuned to the material reality of inequality. That this is a real problem has been apparent in the way Foucault's understanding of power has been imported into the social sciences: prevailing theorizations of disciplinary governance have been unable to do justice to, let alone account for, the growing inequalities that have marked the neoliberal era. Power, in such perspectives, loses its sting. To a large extent, that is why political economy, even when it has been mindful of the epistemological implications of postfoundational thinking, has retained a strong 'meat-and-potatoes' character, often layering a theoretically naïve, idealist constructivism on top of a basic materialism.

So it often seems that we are forced to choose between a way of doing social science that is theoretically sophisticated on the one hand and one that is critical, consequential and realistic on the other. The notion of leverage tries to chart a course out of this impasse. It aims to theorize power as working in a purely performative and relational way while still being able to do justice to the reality of inequality and domination. Patterns of leverage emerge through the interactive processes whereby some begin to identify with discursive and symbolic logics

\section{Corresponding author:}

Martijn Konings, Department of Political Economy, University of Sydney, NSW 2006, Australia.

Email: martijn.konings@sydney.edu.au 
that reflect the interests of others, and so develop identities and roles inflected by those hegemonic interests. In Kantian terms, leverage refers to the way my conditions of possibility double as your conditions of possibility, so that you, simply by pursuing the interests that you have in virtue of the identity you have constructed and need to maintain, are advancing my interests as well - while the same may not be true the other way round. The operation of institutions should be seen through this lens: they do not enjoy substantial reality in and of themselves, but, through their configuration, position some identities more centrally in the fabric of human life than others, thereby amplifying and extending their influence.

I introduced the concept of leverage in my first book (2011) in the context of an engagement with institutionalist problematics; I relied on it in my second book (2015a) to think about how patterns of affective attachment work to produce more or less coherent identities; and it plays a central role in Capital and Time, where I found it a particularly useful way to think about power and control in a context of pervasive epistemic uncertainty. It is possible to detect a shift in the way I use the concept over the course of this trajectory (which only became clear to me when I started thinking more systematically about the role of this concept in my work in response to the reviews here). In the earlier iterations of the concept, even as I stressed the contingent, bricolage-like nature of the way in which social connections are formed, I still placed considerable emphasis on the advantages that elite actors enjoy in reading and manipulating the complexities of social life. Capital and Time, by contrast, emphasizes the role that leverage plays in constructing patterns of power in situations of pervasive uncertainty, where no actor enjoys privileged foresight and there is no way to transcend the need to engage the future in a speculative way. When I am no more capable than anyone else of making accurate predictions about the direction of social life, the best way to optimize my chances of survival is to position myself as a critical hub of connections - so that when risks to my security manifest, others will feel it to be in their own interest to support my survival. If I can issue promises that circulate as the infrastructure of economic life, my conditions of possibility will effectively double as others' conditions of possibility. Banks have learned this trick most effectively: they specialize in leveraging, issuing debt that circulates, thereby ensuring that the public is invested in keeping them afloat (Sgambati, 2015).

This entails greater emphasis on the passive aspect of leverage. What matters is not simply the way I position myself vis-à-vis others, but rather the way others become invested in the reproduction of my identity. This logic of induced investment is one of the defining characteristics of neoliberalism: the imperative it imposes is not simply to make smart investments but to induce other people to invest in me and so to bid up the value of my capital (Feher, 2009). The mechanism at work here becomes apparent when uncertainty is acute, when the powerful can often sit back as the rest of us scramble to prop up the hegemonic institutions in which we have become invested. The financial crisis of a decade ago provided ample evidence of this logic: although the bailouts of large banks provoked an extraordinary degree of anger, it was throughout evident that they were entirely necessary. In such moments, power manifests its banal face, its non-representational character or even its sheer stupidity. The way in which the banks weigh-in on the emerging future is unsophisticated, above all a function of the threat they pose. Joseph Vogl (2014: 153) has usefully grasped this in terms of the rise of a new form of sovereignty, which is bound up not with the possibility of transcending the ordinary field of risk but with the possibility of "transforming [one's] own risks into the dangers of all others".

This is where some of my interlocutors, in particular Jacqueline Best and Matthias Thiemann, express some reservations about my claims. They are not convinced that my work has distanced itself effectively from assumptions that elites 'know what they are doing' or that 
policymakers have an effective overview of the system at large. Instead, they discern a residual teleology or functionalism in my approach that undermines my claim to have moved towards a non-foundational theory. To be sure, I often feel that my entire intellectual trajectory has been driven by an emerging awareness that elements of essentialism or foundationalism lingered where I thought I had gone beyond them. So from that angle it would be incongruous to deny the possibility that these critiques are onto something. Yet I remain unconvinced by the specific arguments advanced by Best and Thiemann.

Over time, I have come to feel that The Development of American Finance (2011) retained a certain Hegelianism when it comes to thinking about the role of the state - not in the sense that it mistakes the appearances of the state for its substance (a problem most prominently associated with the Weberian 'bringing the state back in' literature) but rather in the sense that it was insufficiently specific about the mechanisms whereby challenges to more direct, traditional forms of authority work to facilitate the growth of more distinctly modern, infrastructural forms of state power. ${ }^{1}$ In particular, that book placed insufficient emphasis on the specific role of failure, of gambles gone wrong. But in Capital and Time, failure is front and centre. The book aims to theorize how patterns of power are built in a world without a known destiny and where failure is both inevitable and unpredictable. So, when Thiemann (2018: 195) asks how "monetarism [can] have been a plan so well made and executed?" it is difficult for me to recognize this as accurately reflecting the narrative I present. One of the book's central points is that monetarism was not the move of a mastermind - it was a gamble and could have failed spectacularly. Volcker didn't so much have a plan, but rather a sense that something needed to give and that a major policy turn needed to be forced.

Best (2018) contextualizes the issue in a different way, taking up and challenging my take on actor-network theory. She engages my claim that a useful contrast can be drawn between early actor-network theory and the more recent work of its key exponents, which has reimported an idealism that hides behind a critique of economism. Best agrees there is something to my critique of the evolution of actor-network theory but, noting that there is a close affinity between my notion of leverage and the way early actor-network theory understood the logic of enrolment and inscription, she argues that I could have done more to explore the contributions of early actor-network theory. She views the latter as providing a more rigorous framework for thinking about the material logistics of contingent, speculative connections. Pursuing this argument, she highlights the contingencies and failures that beset the processes through which monetarism was produced and evolved. Rejecting what she perceives as the teleological overtones of my narrative, she argues that monetarism not only had to pass through a long series of mediations to become a political force but also that it was limited in duration and impact.

I agree that the literal implementation of monetarism was short-lived; indeed, I point out that those in charge of monetary policy never thought of monetarism as a coherent doctrine, and that it mostly provided a useful way to introduce policies that would otherwise have been hard to justify and stick with. In the latter capacity, however, it played a key role in transitioning the US political economy from one institutional context to another. Of course, wage repression and changing fiscal policies played a key role in this respect; but the successful adoption of such policies should be understood against the background of how the Volcker shock had adjusted key institutional parameters and had so taken the 'muddling through' option off the table. By presenting wage repression and fiscal austerity as policies that reversed (but did not in key ways alter) the Keynesian logic of the post-war political economy, Best in my view downplays the novelty of neoliberalism and in particular the distinctive way in which it has continued to deploy financial logics (for instance, the way in which the management of price 
inflation has become intricately bound up with the management of asset inflation). The monetarist turn was enormously consequential - not because it was a careful implementation of a coherent theoretical design, but because it was a successful gamble that managed to fully activate patterns of leverage that had been built up in previous years.

It is entirely true that monetarism never produced a world governed by the quantity theory of money, and that instead it emerged and evolved through many material mediations, political affiliations and ideological mutations. But it is only when we assess the practical relevance of a doctrine by the degree to which it produced a world in its image that we need to see those factors as compromising its reality or blunting its force. I would rather think of such associations as the very mechanisms by which a notion acquires its force and engenders new practical logics. This is in keeping with the insights of early-actor network theory, and it is there - much more so than in the emphasis on contingency as such - that I believe its significance resides.

At stake here is the status of contingency in historical explanation. Elsewhere (Konings, 2015c) I have discussed a key ambiguity in the constructivist approach to political economy: while its ostensible purpose would seem to be in analyzing how reality emerges through chains of associations and mediations, in practice it is often simply a stance on the professional politics of knowledge, which cites the constructedness of things in support of its critique of both neoliberal and marxisant claims for the solidity and cohesion of existing institutions. I agree that a renewed engagement with early actor-network theory is a very promising way to move past this worn-out rhetorical move, but it seems to me that this also requires a more decisive break with the implicit belief that demonstrations of the constructed nature of the present by themselves constitute evidence for its lack of coherence or the absence of overarching logics.

Although Best's approach is certainly much more sophisticated than a standard idealist constructivism, she still relies on what I tend to think of as a counterfactual approach to the role of historical contingency. From such a perspective, the importance of thinking historically is that it allows us to counter claims regarding the naturalness or necessity of the present by exposing the elements of contingency that went into its making. In a world where the nearcollapse of the financial system has become an occasion for a renewal of its centrality in socio-economic life, I am not always sure that demonstrating the contingent character of things by itself amounts to a meaningful form of critique. I am, of course, on board with the critique of teleology if that means rejecting readings of history that assume it is driving towards a specific end-goal. But it is increasingly difficult to find thoughtful people who would subscribe to such a point of view. And the preoccupation with the dangers posed by essentializing narratives has diverted significant amounts of mental energy from tracing the vectors, rationalities, path-dependencies, and orientations that have given a determinate direction to history.

So, while both Best and I appreciate the contributions of early actor-network theory, I would still insist that the idealist turn taken by prominent actor-network theorists as they moved into the study of finance is not accidental but reflective of a deeper conceptual problem. The idealist turn is the flipside of a materialism that was always rather essentialist. The latter fact, long effectively hidden under actor-network theory's casual anti-Marxism, was bound up with the under-theorization of what is involved in the emergence of an association between two entities. As I emphasize in Capital and Time, any plausible account of how elements combine with other elements needs to register that this involves a breaching of immanence, a rupturing of material self-sufficiency. It is an insight central to the pragmatic semiotics of Charles Peirce and the pragmatic sociology of George Herbert Mead, on which I 
rely in The Emotional Logic of Capitalism (2015a), that the world of meaning is triadic: the creation of a new connection involves a reflexive moment of triangulation, in which the relation between two elements is imagined from a third point that makes available a new perspective. No association is purely contingent in the sense that it is arbitrary, simply the product of an unforced play of difference; every relation involves an element of strategizing and introduces elements of leverage and control. That is to say, all associations are investments.

I appreciate that it is hard to dissociate this strategic or reflexive element from notions of 'thinking' or 'consciousness'. I myself am certainly not cognitively capable of producing an image of the former without modelling it on the latter - after all, the moment when an entity begins to relate to itself, as if it were not simply itself but more than itself, is irreducibly paradoxical. Nevertheless, taking that cognitive limitation as a reason to proceed with business-as-usual and to evade the paradox will only lead back to subject-object dichotomies and endless attempts to bridge the divide through contrived theoretical innovations. That is why Luhmann's appreciation of the role of paradoxes is so important: rather than seeing them as nonsensical propositions to be avoided or eliminated, he viewed them as the strange formulations that emerge when we reach the outer limits of the frameworks we are working within. As such, he took them as vital clues to the logic on which a system or institution operates and the constitutive blind spots on which it is constructed. Paradoxes tell us something about the unavoidable element of self-referentiality that is embedded in the operation of any systemic logic and as such they are privileged points of entry when it comes to understanding how determinate entities are possible in a world that lacks foundations and where every move is a speculative one.

Luhmann plays a central role in scaffolding the argument of Capital and Time because he provides a more compelling understanding of how associations come into being and operate than actor-network theory does. In particular, I argue that the paradoxical self-referentiality of money provides an extremely useful set of clues to the speculative operations at the heart of capital. This involves an unusual appropriation of Luhmann that departs from the established interpretation, which tends to focus on his understanding of society in terms of the interaction of differentiated subsystems. Leon Wansleben (2018) questions the usefulness of this move, arguing that the more traditional Luhmannian scheme is quite consistent with some of my claims. Wansleben's grasp of the intricacies of Luhmann's work clearly exceeds my own, and it may very well be the case that I have failed to appreciate some of the possible uses offered by the received interpretation of Luhmann's work. But I am not sure that it negates the importance of reconstructing a version of Luhmann that is more radical and critical than the one we have been given so far. For instance, the way Wansleben translates my argument into a different Luhmannian language is accurate enough, but I have the sense that more traditional Luhmannian scholars would have the same kinds of issues with it as Wansleben does with my version. It seems to me that the core rationale for Luhmann's claim to be offering a radical constructivism has to consist not in the fact that society consists of subsystems that cannot communicate with each other, but in the fact that any system is self-referential and therefore cannot generate a totalizing point of view from which it can diagnose its blind spots and assess itself in objective, neutral terms. There is an important shift in emphasis here: whereas the former keeps us close to conventional problematics, the latter can serve as a new resource of critique. If we picture society in terms of the interaction of self-referential subsystems, the most we can hope for is a problematic of 'relative autonomy', exactly the kind of critical paradigm that gets irresolvably stuck in dichotomies of the material and the ideal. ${ }^{2}$

The counterfactual logic of constructivist historical reasoning becomes more apparent in the reservations expressed by Thiemann, which revolve around the concern that I do not give 
sufficient weight to the plans and intentions of key actors. He highlights in particular the plans for more coherent system-level regulation that circulated among policymakers in the aftermath of the crisis. These include "new capital surcharges for global systemic financial institutions, but also requirements to create 'living wills', as well as decisions to increase the lossabsorbing capacity of large banks" (Thiemann, 2018: 195). According to him, such initiatives should be taken more seriously than they are in Capital and Time:

One can characterize [them] as an ordoliberal pipedream of recreating a direct match between profits and entrepreneurial responsibility, or of reinstating market discipline and of thereby ending 'too big to fail', but one cannot simply ignore [them]. (Thiemann, 2018: 195-96).

But the book doesn't ignore them - far from it. I argue that these attempts to manage system risk with new instruments should be seen as an evolution of distinctly neoliberal practices and modes of governance. They are certainly not pipedreams; instead, they are conceptual devices embedded in neoliberal practice. I do appreciate that, in reframing the significance of these innovations in this way, I am giving short shrift to the good intentions held by some people who could not (or did not want to) see that these new instruments were going to facilitate the resurrection rather than suppression of capital. But perhaps we don't always need to care about people's ideas in the specific way that they would like us to.

At work in Thiemann's objection, I believe, is a tendency to conflate agency and consciousness. Although Thiemann summarizes my critique of rational constructivism with great insight and a number of formulations that I wish I had come up with myself, it is difficult to escape the conclusion that it is precisely that paradigm that he is reluctant to let go of entirely. When he writes that "repeated reference to Luhmann seems to suggest a doing-away with agency - after all, Luhmann was clearly opposed to any theory of agency" (Thiemann, 2018: 196), he stays close to the common interpretation of Luhmann's work which mistakes his rejection of transcendental theories of agency for a rejection of agency altogether. If we read Luhmann against the grain, I do not think it is possible to see him as evacuating agency. Luhmann was certainly opposed to voluntarist theories of agency that oppose it to the structuring effects of systems. But what he provided instead was a radical, non-essentialist theory of agency. For him, the emergence of agency and the process of system formation are closely related, indeed essentially identical processes: agency is what Daniel Dennett (1984) referred to as the "elbowroom" that emerges with the evolutionary logic of system formation.

Such elbowroom, however significant, never flips over into an ability to comprehend the social field in its totality or to manipulate it through clean, externally originated interventions. It is only ever leverage, an enhanced ability to both provoke and benefit from volatility in the social field. Leverage is at its core speculative - it exists awkwardly between on the one hand the impossibility of self-contained material subsistence and on the other hand the impossibility of reflexivity ever escaping the material conditions from which it emerged. Of course, the pragmatic logic of triangulation through which we construct new associations and investments can at times appear to be highly strategic, driven by complex calculations and sophisticated assessments of risk. But such appearances of precision are undone when volatility threatens to tip over into full-blown crisis and patterns of power operate in a much blunter, blackmail-like manner.

Leverage is the modality whereby determinate patterns of power and control are constructed in a world without foundations. As such, it has a privileged relationship to modernity. The distinctive characteristic of modern life is the (often implicit but all-too-real) awareness that that there exist no outside criteria, no known destiny, no external measures 
against which we can judge the value of our investments. As Leigh Claire La Berge (2018: 201) puts it in her discussion, "To be a creature of modernity, one is forced to leverage what one has. One can't recuse oneself from leveraging. One cannot get outside of a leveraged world". Neoliberalism as a rationality of governance has intuited and exploited this very effectively, in ways that its progressively minded critics have generally been unable to recognize. In Capital and Time I work this out in terms of Hayek's critique of rational constructivism and its relationship to systems theory, but that is obviously not to suggest that neoliberalism started off as a specific philosophical innovation that was then propelled into real-world action. Instead, this theme is one point of entry (among others) that allows us to grasp the operation of neoliberalism as a practical rationality, which works in diffuse, contingent and indirect ways. In other words, the strength of neoliberalism has always resided not in the production of a theoretical master plan, but in the ability to do something productive with the awareness that the successful execution of a master plan is inherently impossible. Characterized by a tremendous degree of comfort with the speculative dimension, it has developed the logic of leverage into an economy of provocation and blackmail.

I appreciate that these considerations by themselves will not convince anyone who is invested in seeing economism, structuralism, functionalism and teleology as the primary dangers. To advance a critique that emphasizes the constitutive role of the perceptual blind spot while still expecting that critique to find traction without delay would be very naïve. This is why the book does not explore in great detail the nuances of field-specific debates - someone who is not willing to give my argument a run for its money is unlikely to be convinced by such specifics. It has its sights set farther afield: selectively taking up key themes in political economy and social theory, it goes as far as it can in showing what becomes visible by adopting the particular angle it proposes. Pinning its hopes of rhetorical traction in a crowded field on the demonstration of analytical payoff, it banks on the experiential 'a-ha' moment of new insight.

Thiemann's take on the critical project of Capital and Time is therefore entirely accurate and worth repeating. As he puts it, the book

follows in [its] critical endeavor the epistemological and ontological commitment expressed in [its] analysis of capitalism, in which any (theoretical) investment is an act of speculation, which gains validity by inscribing itself into a larger network of (analytical) promises. Given the impossibility of discerning externally valid criteria for critique, [it] is making a speculative investment with [its] own proposal, hoping that others find it useful for their own speculative venturing in the theoretical terrain. (Thiemann, 2018: 197)

Thiemann is not without appreciation for the content of the project, but he nonetheless seems to feel that this style of critical analysis is inherently somewhat nihilistic, the result of having imbibed too much of the neoliberal post-truth Kool-Aid. I accept that my project, by denying the viability of many of the political strategies on which we tend to pin our hopes for the future, may engender a certain bleakness. Perhaps I am just more capable than others of living in a desert of negative critique, devoid of hope for better futures - but I highly doubt it. Personally I find nothing more soul-destroying and life-negating than the false optimism that continuously leads us to look to policymakers and politicians for interests and capacities that they patently do not possess, only to subsequently and predictably engage in the ritual lamentation of missed opportunities and the 'failure to learn lessons'. What gets suppressed in the process is a kind of conceptual curiosity that I think is far more politically valuable than it is typically given credit for. 
Although I am convinced such curiosity needs to start with an engagement of the negative, I do not think there is any necessary reason that it needs to remain stuck in negative critique. The encounter with the negative is a constructive moment, where new things can happen. La Berge questions what she perceives as my overly austere understanding of the possibilities of critique suggested in the passage that she cites at the start of her review. And she argues that a more in-depth engagement with work that has brought the resources of literary critique to bear on questions of money and finance would be extremely helpful in developing the positive characteristics of a post-foundational critique of contemporary capitalism. I agree with this point. The argument that critique never escapes the performative condition - in the specific sense that it never becomes a matter of holding reality up against a set of external norms - has its specific relevance in the context of the intersection of political economy and social theory that is targeted by the book's argument. But I recognize that much could be gained from breaking out of the specific interdisciplinary universe that Capital and Time inhabits and engaging more thoroughly with humanities scholarship, literary critique, as well as the worlds of art and activism.

Although I have few doubts about the value of such a project, I do not consider myself remotely qualified to undertake it. Or perhaps I just am just acutely aware of how much remains to be done when it comes to conceptualizing the core categories of political economy. That is probably one of the reasons why, whereas my previous book 'opened out' financial issues onto various other traditions of knowledge, Capital and Time works more by 'drawing in' select resources from social theory to reconstruct our understanding of money, finance and capital and how they are governed - which are classic questions of political economy. In this way it has sought to push back against the scientism (which typically goes by the name of 'disciplinary rigor') that is so rampant not just in economics but equally in political science and sociology, and which serves as a major obstacle to making the insights of post-foundational theory fully relevant to our understanding of money, the most emphatically symbolic institutions that we have.

\section{Notes}

1. See my review of Knafo's (2013) book for further reflections on this (Konings, 2015b).

2. For instance, see Jessop's (1990) incorporation of autopoiesis into state theory.

\section{References}

Best, J. (2018) Recovering the mundane practices of economic time. Finance and Society, 4(2): 18187.

Dennett, D. (1984) Elbow Room: The Varieties of Free Will Worth Wanting. Cambridge, MA: MIT Press. Feher, M. (2009) Self-appreciation; or, the aspirations of human capital. Public Culture, 21(1): 21-41. Jessop, B. (1990) State Theory: Putting the Capitalist State in its Place. Cambridge: Polity. Knafo, S. (2013) The Making of Modern Finance: Liberal Governance and the Gold Standard. London: Routledge.

Konings, M. (2011) The Development of American Finance. Cambridge: Cambridge University Press. Konings, M. (2015a) The Emotional Logic of Capitalism: What Progressives Have Missed. Stanford, CA:

Stanford University Press.

Konings, M. (2015b) Historicising finance. Progress in Political Economy [Blog], 5 October. Available at: <http://ppesydney.net/historicising-finance/>. Accessed 8 November 2018. 
Konings, M. (2015c) What is constructivism for? Progress in Political Economy [Blog], 18 February. Available at: <http://ppesydney.net/what-is-constructivism-for/>. Accessed 8 November 2018.

Konings, M. (2018) Capital and Time: For a New Critique of Neoliberal Reason. Stanford, CA: Stanford University Press.

La Berge, L.C. (2018) Money is time: On the possibility of critique after neoliberalism. Finance and Society, 4(2): 199-204.

Sgambati, S. (2015) Rethinking banking: Debt discounting and the making of modern money as liquidity. New Political Economy, 21(3): 274-90.

Thiemann, M. (2018) On the constitutive effects of contingent associations. Finance and Society, 4(2): 193-98.

Vogl, J. (2014) The sovereignty effect: Markets and power in the economic regime. Qui Parle, 23(1): 125-55.

Wansleben, L. (2018) Luhmann without society. Finance and Society, 4(2): 188-92. 